\title{
ÉTICA E INTEGRIDADE NAS INSTITUIÇÕES DE ENSINO SUPERIOR: A IMPORTÂNCIA DA IMPLEMENTAÇÃO DE PROGRAMAS DE COMPLIANCE NAS UNIVERSIDADES
}

\author{
ETHICS AND INTEGRITY IN HIGHER EDUCATION INSTITUTIONS: THE IMPORTANCE OF \\ IMPLEMENTING COMPLIANCE PROGRAMS IN UNIVERSITIES
}

\section{Bruna Azzari}

Mestre em Direito Político e Econômico pela Universidade Presbiteriana Mackenzie (2020).

Bacharel em Direito pela Universidade Presbiteriana Mackenzie (2012/2016). Membro do Grupo de Pesquisa Estado e Economia no Brasil ligado ao Programa de Pós-Graduação em Direito Político e Econômico da Universidade Presbiteriana Mackenzie.

E-mail: bruna.azzari@hotmail.com

\section{Amanda Scalisse Silva}

\begin{abstract}
Mestre em Direito Político e Econômico pela Universidade Presbiteriana Mackenzie (2020). Bacharel em Direito pela Universidade Presbiteriana Mackenzie (2013/2017).

E-mail: amandascalisse@gmail.com
\end{abstract}

\section{Felipe Chiarello}

\begin{abstract}
Mestre e Doutor em Direito pela PUC/SP. Professor Titular da Faculdade de Direito e do PPGD da Universidade Presbiteriana Mackenzie, onde foi Diretor da Faculdade de Direito e atualmente é Pró-Reitor de Pesquisa e PósGraduação. Professor Colaborador do PPGD/UPF. Coordenador Adjunto de Programas Acadêmicos da Área de Direito da CAPES-MEC e Bolsista de Produtividade em Pesquisa do CNPq. E-mail: felipechiarello@gmail.com
\end{abstract}

Recebido em: $15 / 05 / 2020$ Aprovado em: 08/09/2020

RESUMO: O artigo discute a necessidade da implementação de programas de compliance nas instituições de ensino superior como instrumento de garantia da ética e integridade. Utilizou-se o método dedutivo, sob uma abordagem bibliográfica quantitativa, para analisar a existência de mácondutas científicas, a necessidade de regulação interna, e como instrumentalizar isso nas IES. Para isso, verificou-se a necessidade de contextualizar a governança corporativa e o compliance a partir do conceito de diminuição de assimetrias informacionais e conflitos de gestão. Após, analisadas as fragilidades existentes na atividade educacional das universidades, foi verificada a sua possibilidade de implementação nessas instituições. Constatou-se que o programa de compliance é o meio mais eficaz de criar uma cultura de integridade nas universidades, combatendo não só práticas corruptas, mas a má conduta na pesquisa.

Palavras-chave: Compliance educacional. Ensino Superior. Ética. Integridade. Má conduta científica. 


\begin{abstract}
The article discusses the need to implement compliance programs in higher education institutions, as an instrument to guarantee ethics and integrity. The deductive method was used, under a quantitative bibliographic approach, to analyze the existence of scientific misconduct, the need for internal regulation, and how to implement this in HEIs. Therefore, there was a need to contextualize corporate governance and compliance based on the concept of reducing information asymmetries and management conflicts. After, analyzed the weaknesses that exists in the educational activity of universities, the possibility of implementation in these institutions was verified. It was found that the compliance program is the most effective means of creating a culture of integrity in universities, combating not only corrupt practices, but misconduct in research.
\end{abstract}

Keywords: Educational Compliance. Higher Education. Ethics. Integrity. Scientific Misconduct.

SUMÁRIO: Introdução. 1. Governança corporativa e compliance. 2. Assimetrias informacionais e conflitos de interesse existentes na atividade de Instituições de Ensino Superior. 3. A importância da implementação de Programas de Compliance em Instituições de Ensino Superior. Considerações Finais. Referências

\title{
INTRODUÇÃO
}

O presente artigo tem como objetivo central a investigação da possibilidade e da necessidade de implementação de programas de compliance nas universidades para garantia da ética e integridade em suas atividades.

Justifica a presente pesquisa o fato de que a educação superior no Brasil faz parte de um nicho extremamente regulado, que, nos termos do artigo 209 da Constituição Federal, estão as instituições de ensino privadas sujeitas à autorização e avaliação regular do Poder Público para exercer a atividade.

Dessa forma, a partir da reação social à denúncias de práticas corruptas e antiéticas no âmbito da Administração Pública, crescente nas últimas décadas, toda e qualquer atividade que se relaciona com entidades e órgãos estatais, dentre elas a educação de ensino superior, têm sido objeto de análise para melhoria e redefinição com base em preceitos éticos e legais.

Tal cenário, trouxe impactos que representam profunda adaptação de modelos e conceitos jurídicos que envolvem as referidas atividades, até então estranhos a nosso ordenamento e costumes, tais como a implementação de programas de integridade e compliance.

Assim, como objetivos específicos verifica-se a necessidade de contextualizar a governança corporativa e o compliance a partir do conceito de diminuição de assimetrias informacionais e conflitos de gestão, para, após, analisar as fragilidades existentes na atividade educacional das universidades e, por fim, a possibilidade de implementação de programas de integridade nas instituições de ensino superior.

Para tanto, utilizou-se o método dedutivo, que permite uma construção lógica de raciocínio, em ordem descendente de análise, em que são escolhidas duas proposições como base de estudo, chamadas premissas, para que possa ser retirada uma terceira, denominada conclusão. Em relação aos objetivos apresentados, a presente pesquisa se configura como exploratória, pois visa proporcionar maior familiaridade com o problema, com vistas a torná-lo explícito ou construir hipóteses, através da utilização de levantamento bibliográfico.

\section{GOVERNANÇA CORPORATIVA E COMPLIANCE}

Nas sociedades democráticas, as instituições de governança do Estado são adotadas à medida que o exercício da cidadania se aprofunda. Tais sociedades passam a definir os mecanismos pelos quais seus governantes são monitorados por meio de um conjunto de regras formais

Revista de Direito Brasileira | Florianópolis, SC | v. 26 | n. 10 | p. 457-470 | Mai./Ago. 2020 
resultantes da interação de diferentes atores sociais. O exercício e o cumprimento da lei passam a ser função não somente do aparato legal existente, mas também da pressão informal exercida pelas instituições e sociedade civil no cumprimento e na melhoria dessas regras (MACHADO FILHO, 2016).

Analogamente, as organizações privadas também criam mecanismos de governança para lidar com a delegação de poder. A gênese de uma organização que nasce e cresce no mercado, de forma simplificada, passa por algumas etapas: primeiro o "dono" cria a empresa; com o tempo a companhia cresce; o dono não mais executa as atividades gerenciais sozinho; assim, a empresa passa por sucessivos processos de delegação e o "dono" se vê obrigado a implementar mecanismos de incentivo e monitoramento, para que os agentes aos quais ele delegou poderes estejam alinhados com as suas expectativas (MACHADO FILHO, 2016).

Nesse cenário surge a governança corporativa, cujo desafio central é a minimização de assimetrias e conflitos de interesses inerentes à delegação de poder através do alinhamento da empresa na busca de eficiência e eficácia empresarial (BECHT, BOLTON, ROELL, 2002).

O conceito clássico de governança corporativa, originado pela necessidade de mecanismos de regulação e controle das atividades de gestão, concebidos em defesa dos interesses do controle acionário, cede espaço ao movimento de governança corporativa "social", consistente em uma extensão da teoria de agência oriunda de estudos organizacionais de origem sociológica, segundo a qual não somente os proprietários outorgam aos gestores poder decisório para maximizar seus interesses (ANDRADE, ROSSETTI, 2006, p. 137).

$\mathrm{O}$ conflito de agência surge quando um determinado agente age em nome de outro, o chamado principal, e os objetivos de ambos não coincidem integralmente. Assim, numa relação principal/agente, como, por exemplo, empregador/empregado, acionistas/executivos ou instituidores/executivos, o principal busca implementar uma estrutura de incentivos e monitoramento, visando alinhar os interesses do agente aos seus (CHIARELLO; SCALISSE, 2019, p. 367).

A definição de governança corporativa ainda não é pacificada, pois sua existência não só é ainda muito recente, mas também está inserida num contexto de diversidades bastante amplo no que se refere à sua aplicação prática no âmbito das empresas, que fica a submetida a diversas variáveis e critérios, tais como: a dimensão da empresa; sua estruturação societária; a composição e a estruturação de seu financiamento; o nível de regulação estatal a que está submetida; a tipologia legal em que está enquadrada; a origem do capital de seu grupo controlador; a sua abrangência geográfica e características culturais do países em que opera; os marcos legais e regulatórios desses países (ANDRADE, ROSSETTI, 2006, p. 137 et. seq.).

Tendo em vista este conjunto de diversidades em que está inserida, bem como considerando sua relativa novidade no mundo corporativo, a conceituação de governança corporativa pode ser dividida em quatro grupos principais: (i) guardiã de direitos das partes com interesses em jogo nas empresas; (ii) sistema de relações pelo qual as sociedades são dirigidas e monitoradas; (iii) estrutura de poder que se observa no interior das corporações; (iv) sistema normativo que rege as relações internas e externas das companhias (ANDRADE, ROSSETTI, 2006, p. 138 et. seq.).

Sob qualquer um dos prismas que pode ser conceituada a governança corporativa, é certo que têm eles pontos em comum: o respeito e a obediência ao sistema legal em que a organização opera e está inserida, e o aprimoramento das relações interpessoais e de poder.

Assim sendo, conforme descrito no Código de melhores práticas de governança corporativa, os princípios básicos de governança são:

a) Transparência: Consiste no desejo de disponibilizar para as partes interessadas as informações que sejam de seu interesse e não apenas aquelas impostas por disposições de leis ou regulamentos; 
b) Equidade: Tratamento justo e isonômico de todos os sócios e das demais partes interessadas, levando em consideração seus direitos, deveres, necessidades, interesses e expectativas;

c) Prestação de contas (accountability): Os agentes de governança devem prestar contas de sua atuação de modo claro, conciso, compreensível e tempestivo;

d) Responsabilidade corporativa: Os agentes de governança devem zelar pela viabilidade econômico-financeira das organizações, reduzir as externalidades negativas de seus negócios e suas operações e aumentar as positivas, levando em consideração, no seu modelo de negócios, os diversos capitais (financeiro, manufaturado, intelectual, humano, social, ambiental, reputacional etc.) no curto, médio e longo prazo. (IBGC, 2018).

Destarte, para atingir seus objetivos, as técnicas de governança corporativa adotam, como linhas mestras de ação, a transparência administrativa, a responsabilidade na prestação de contas, a equidade e a responsabilidade corporativa, sendo que, de eventual falha, podem ocorrer consequências nefastas para a companhia, decorrentes de abusos de poder (seja do acionista majoritário sobre minoritários, dos executivos sobre os acionistas ou mesmo dos administradores sobre terceiros), erros estratégicos (consequência de excesso de poder concentrado nas mãos de poucos executivos) e fraudes (utilização de informações privilegiadas para benefício próprio, iniciativas em conflito de interesses, desvios patrimoniais) (SARCEDO, 2016, p. 41).

Nesse contexto surge o compliance, que, derivado do verbo da língua inglesa to comply, significa cumprir, estar em conformidade, estar de acordo, e refere-se à aderência a leis e regulações (FLORÊNCIO FILHO; ZANON, 2019, p. 417). Compliance estabelece, portanto, uma relação entre um "estado de conformidade" e uma determinada "orientação de comportamento". Se essa "orientação de comportamento" é uma norma jurídica, está-se diante de compliance jurídico, suja designação varia de acordo com área do direito, na qual a norma a ser seguida se insere (SAAVEDRA, 2019, p. 41).

No Brasil, o interesse pelo tema surgiu com mais intensidade após a edição da Lei Anticorrupção (Lei ${ }^{\circ}$ 12.846/2013), a qual prevê que a adoção de mecanismos e procedimentos internos de integridade e a aplicação efetiva de códigos de ética e de conduta no âmbito da pessoa jurídica será levada em consideração na aplicação de sanções administrativas pela prática de atos lesivos à Administração Pública (CHIARELLO; SCALISSE, 2019, p. 212).

Apesar de comumente aludido como estratégia de combate à corrupção, tendo em vista a possibilidade de criminalização da pessoa jurídica na hipótese de ato de corrupção contra a administração pública trazida pela mencionada lei, o compliance vai muito além desta única função, sendo um importante mecanismo de gerenciamento de riscos.

Com utilização crescente nas mais diversas organizações públicas e privadas, os programas de integridade passaram a ser implementados também nas universidades, cujos conflitos e assimetrias inerentes à atividade se passa a analisar.

\section{ASSIMETRIAS INFORMACIONAIS E CONFLITOS DE INTERESSE EXISTENTES NA ATIVIDADE DE INSTITUIÇÕES DE ENSINO SUPERIOR}

A educação superior no Brasil faz parte de um nicho extremamente regulado. Além das universidades públicas, as instituições da livre iniciativa também estão sujeitas à avaliação e autorização do Poder Público para exercer sua atividade, estando, inclusive, conforme previsão do artigo 209 da Constituição Federal, submetidas às normas gerais da educação nacional.

No que se refere ao ensino superior, objeto do presente artigo, os atos administrativos que envolvem a relação das instituições e o Poder Público vão desde o credenciamento e recredenciamento das instituições e cursos, até a avaliação periódica da qualidade do ensino.

Tenório e Andrade explicam que: 
No campo educacional, as novas diretrizes do século XX e início do século XXI têm sedimentado um novo perfil de gestão, sobretudo nas organizações universitárias, no qual está presente um conjunto de características, dentre as quais, a flexibilidade, a agilidade, a eficiência, a eficácia, a relevância e a produtividade. A universidade é vista não apenas como um centro de formação de saberes e produção de conhecimento, mas como aquela que atende aos princípios básicos da modernidade, seja no que se refere às relações de trabalho, ou à prestação de serviços à sociedade.

No âmbito da educação superior, a avaliação tem sido estimulada, através de ações diretas dos governos com a criação de agências nacionais de avaliação para dar conta da expansão, diversificação desse nível de ensino. (TENÓRIO; ANDRADE. 2009. p. 32)

Nesse sentido, para proteger a qualidade educacional do ensino superior, e no intuito de atender a princípios da modernidade, tal qual a prestação de serviços à sociedade, a Constituição Federal de 1988, em seu artigo 207, consagrou o princípio da indissociabilidade entre ensino, pesquisa e extensão, apontado como:

[...] referência do padrão de qualidade acadêmica para as instituições de ensino superior do país, que se baseia na negação das desigualdades sociais (que abrange a distribuição desigual dos bens, inclusive culturais), expressando assim o papel social da universidade na construção de uma sociedade democrática e igualitária. (SANTOS; PUGA. 2019. p. 41)

Tais princípios basilares do ensino superior são também a essência da avaliação das instituições. Neste cenário podem surgir as assimetrias e conflitos informacionais relacionados às relações das instituições de ensino superior com órgãos e entidades externas, tendo em vista que, não somente os funcionários de tais instituições, como também os próprios funcionários públicos responsáveis pelas avaliações e autorizações das atividades das universidades e pela concessão de incentivos do poder público para as mesmas, à margem dos limites éticos e legais, podem, desconsiderando o interesse público e da instituição, atuar na busca de vantagem particular de modo a fraudar ou corromper o sistema.

Em relação às atividades internas e a produção científica da universidade, a ética e a integridade também devem ser prestigiadas.

É impossível falar de pesquisa acadêmica sem citar a CAPES. A Coordenação de Aperfeiçoamento de Pessoal de Nível Superior é uma fundação do Ministério da Educação, responsável pela expansão e consolidação da pós-graduações stricto sensu do país. Dentre suas atividades, é responsável pela avaliação dos programas, cujo resultado serve de base para a formulação de políticas públicas e para o dimensionamento das suas ações de fomento, quais sejam, bolsas de estudo, auxílios e apoios. (CAPES, 2008). Fundamental para assegurar a qualidade dos cursos de Mestrado e Doutorado no país, a avaliação dos programas engloba a avaliação da pesquisa acadêmica de seus docentes e discentes. Não somente, os concursos de contratação de professores para lecionarem nas graduações utilizam como critério de classificação a sua produção científica.

Dentre os principais instrumentos de apoio às avaliações da CAPES, estão a classificação de livros e o sistema QUALIS-CAPES. Neste último, são formadas listas com periódicos que tiveram publicações de docentes e discentes de programas que compõem o Sistema Nacional de Pós-Graduação (SNPG). Estas listas são utilizadas inclusive na avaliação dos programas de pósgraduação, tanto nas propostas de cursos novos quanto nos cursos em funcionamento (SANTOS; PUGA. 2019. p. 44). Contudo, atualmente há o desvirtuamento dos objetivos das listas Qualis, uma 
vez que são utilizadas principalmente para avaliar o desempenho científico individual dos pesquisadores:

[...] é inquestionável o uso das listas Qualis com outros objetivos, não só pelos próprios programas de pós-graduação em todo território nacional, mas também pelos próprios pesquisadores que o utilizam para avaliar a qualidade dos periódicos que pretendem encaminharem o resultado de suas pesquisas ou ainda, por instituições alheias à Capes que se pautam nessa listagem como mecanismo de aferição do desempenho individual de pessoas, tornando os pesquisadores verdadeiras máquinas de publicações vazias (SANTOS; PUGA. 2019. p. 47).

Além dos periódicos, os livros são um importante meio de difusão das pesquisas de grande relevância na academia, especialmente nas Ciências Humanas e Sociais Aplicadas, nas quais a publicação de livros e capítulos de livro tem destaque igual ou até maior que os artigos. Assim, a CAPES aprovou em 2009 um Roteiro para Classificação de Livros, que serviu como orientação para as áreas que consideraram as produções em livros a partir da avaliação trienal de 2010 (MASSINI-CAGLIARI, 2012, p. 771). Em 2019, com o objetivo de aprimorar o processo de classificação dos livros, foi publicada pela CAPES uma nova proposta de classificação de livros a ser utilizada nas próximas avaliações.

A utilização das listas Qualis e classificação de livros para a avaliação da qualidade científica da produção dos pesquisadores, inclusive em critérios de promoção e comparação entre indivíduos e grupos, dentre diferentes programas e em suas próprias casas, se inserem dentre os diversos fatores que estimulam a sua competitividade, para que produzam mais trabalhos acadêmicos, e disputem por oportunidades de ascensão na carreira.

Ademais, a necessidade de financiamento para as pesquisas, e o árduo processo para obtenção de aprovação das principais agências do país, impulsionam o viés competitivo da produção acadêmica: “O aumento da competição por financiamento pode levar à pressão para obtenção de crédito como a primeira pessoa a desenvolver novas ideias, fazer novas descobertas e / ou publicar novas descobertas, a fim de alcançar a posse e a promoção acadêmica"1 (BINDER; FRIEDLI; FUENTES-AFFLICK. 2016, p.175).

Concorrência, rivalidade, vaidade, ambição, resultam na utilização de métodos pouco, ou nada, íntegros na carreira acadêmica. São as citadas más condutas científicas:

Entende-se por má conduta científica toda conduta de um pesquisador que, por intenção ou negligência, transgrida os valores e princípios que definem a integridade ética da pesquisa científica e das relações entre pesquisadores, tal como os formulados neste código. A má conduta científica não se confunde com o erro científico cometido de boa-fé nem com divergências honestas em matéria científica. (FAPESP, 2014, p.31).

O Código de Boas Práticas Científicas da FAPESP - Fundação de Amparo à Pesquisa do Estado de São Paulo (2014) exemplifica algumas dessas condutas: (i) fabricação de dados, procedimentos ou resultados que não foram conduzidos ou obtidos; (ii) falsificação de dados a ponto de poder interferir na avaliação do peso científico que realmente conferem às conclusões que deles se extraem; (iii) plágio. Além destas, existem outras condutas que demonstram a falta de integridade na pesquisa acadêmica, como o primitivo roubo de ideias não publicadas, o autoplágio, acordos de citação (revistas pedem que autores citem outros trabalhos da própria revista; professores que exigem que seus alunos citem seus livros e artigos), e a "Salami Science":

\footnotetext{
${ }^{1}$ Tradução nossa. Original em inglês: "The increased competition for funding may lead to pressure to get credit as the first person to develop new ideas, make new discoveries, and/or publish new findings, so as to achieve tenure and academic promotion".
} 
"Salami Science" é a prática de fatiar uma única descoberta, como um salame, para publicá-la no maior número possível de artigos científicos. O cientista aumenta seu currículo e cria a impressão de que é muito produtivo. O leitor é forçado a juntar as fatias para entender o todo. As revistas ficam abarrotadas. E avaliar um cientista fica mais difícil. Apesar disso, a "Salami Science" se espalhou, induzido pela busca obsessiva de um método quantitativo capaz de avaliar a produção acadêmica. (REINACH, 2013).

A FAPESP, ainda, publica em sua página um sumário de todas as investigações que tenham conduzido ou supervisionado, e que tenha resultado na constatação da ocorrência de violação do Código de Boas Práticas Científicas, por período limitado, atendendo ao princípio da proporcionalidade. Referente à supracitada competitividade por financiamento para as pesquisas, um dos processos disponíveis na página à época da redação deste artigo (Processo 16/307), retrata a má conduta científica, por meio do plágio, de um pesquisador que teve acesso ao projeto de PósDoutorado de outra pesquisadora, com o aparente objetivo de estabelecer futuras parcerias, e resultou em "figuras e longos trechos copiados do projeto" utilizados na formulação de sua solicitação de Auxílio à Pesquisa; após longa investigação, a FAPESP verificou a veracidade da alegação de plágio e declarou ter havido prática de má conduta grave, advertindo o pesquisador e impedindo-o de solicitar bolsas e auxílios daquela instituição pelo período de 48 meses, além do cancelamento e restituição dos recursos obtidos pelo Auxílio à Pesquisa que havia sido aprovado para a execução do projeto do advertido (FAPESP, 2019).

Sobre a ética em autoria de trabalhos científicos, Sigmar de Mello Rode e Bruno das Neves Cavalcanti (2003) alertam para a consciência da ética na produção estabelecendo um paralelo entre a quantidade, a qualidade, e a autoria das publicações, ao descrever questões de aproveitamento de posição hierárquica para fazer constar um nome na coautoria de trabalho científico, questões de plágio, de formação de grupos de pesquisa para a criação de "fábricas de trabalho, onde cada um faz um e prestigia os outros do grupo", e, inclusive, levantando a questão da relação entre a produção acadêmica e das avaliações institucionais:

Outra situação delicada é a de que para atender a requisitos de avaliações institucionais, muitas vezes quantitativas e não qualitativas, verifica-se pesquisadores com produção de mais de 2 trabalhos por mês (vinte, trinta trabalhos por ano), o que certamente denota a não-participação ou participação superficial na maioria dos projetos. (RODE; CAVALCANTI. 2003, p.2).

Entendemos, é claro, que essa discussão quanto ao número de trabalhos dentro de um dado período difere em cada área de conhecimento, além das especificidades de cada pesquisa, contudo, salienta-se a importância da ética, e do bom senso do pesquisador na atribuição de autoria.

São diversas as condutas reprovadas pela comunidade científica, entretanto, apesar de conhecidas, sempre ocorreram de modo furtivo, sendo recentes as discussões sobre o assunto, assim como os casos expostos publicamente sobre o assunto. Foi um escândalo envolvendo um químico da Unicamp, que teve 11 trabalhos retirados de revistas que os haviam publicado ${ }^{2}$, que teria motivado em 2012 a criação pelo CNPq, uma das principais agências de fomento do país, de uma comissão para avaliar casos envolvendo denúncias de fraude científica.

\footnotetext{
${ }^{2}$ Uma investigação internacional realizada pelo site "retractionwatch.com", que rastreia casos de retratação em revistas científicas, apontou a fraude nos artigos científicos do pesquisador. Os 11 artigos haviam sido publicados por periódico científico da Elsevier, tendo os seus editores afirmado que os sinais de manipulação dos resultados eram conclusivos, isto é, o pesquisador teria falsificado imagens de ressonância magnética que eram fundamentais para a sua pesquisa. Disponíveis em: https://retractionwatch.com/2011/03/28/hazardous-materials-elsevier-retracts-11-chemistry-papers$\underline{\text { from-brazilian-group-citing-fraud/ e http://retractionwatch.com/2011/03/29/elsevier-weighs-in-on-brazilian-fraud- }}$ case/. Acesso em 06 set. 2019.
}

Revista de Direito Brasileira | Florianópolis, SC | v. 26 | n. 10 | p. 457-470 | Mai./Ago. 2020 
Na mesma época, o primeiro Código de boas práticas científicas da FAPESP, estipulava que as instituições de pesquisa com projetos apoiados pela Fundação deveriam criar instâncias encarregadas de promover atividades educativas sobre integridade da pesquisa, de aconselhar alunos e docentes e de investigar e, se for o caso, punir casos de má conduta (RAMOS, 2015).

O contexto no Brasil nada mais do que refletia um problema global. Em 2012, um estudo publicado na revista Proceedings of the National Academy of Sciences of the United States of America (PNAS), identificou que dentre as causas de retratação de 2.047 artigos científicos indexados no importante repositório PubMed, produzidos por pesquisadores de 56 países, apenas $21,3 \%$ foram atribuídas a erro, enquanto $67,4 \%$ foram atribuídas à má conduta científica $(43,4 \%$ por fraude ou suspeita de fraude, $14,2 \%$ por publicação duplicada, 9,8\% por plágio). (FANG; STEEN; CASADEVALL. 2012).

Assim, as universidades devem possuir políticas e procedimentos para lidar, além das fraudes e práticas corruptas, com tais questões de má conduta na pesquisa, sendo o programa de compliance, conforme se passa a analisar, um meio eficaz para criar uma cultura de integridade nas Instituições de Ensino Superior, através da conscientização, investigação, prevenção dos riscos e correção das irregularidades.

\section{A IMPORTÂNCIA DA IMPLEMENTAÇÃO DE PROGRAMAS DE COMPLIANCE EM INSTITUIÇÕES DE ENSINO SUPERIOR}

A atual mudança na exigência social e no perfil de gestão das instituições de ensino nos faz perceber a importância da implementação de programas de compliance no ensino superior de maneira própria e específica como forma de minimizar o risco de não conformidade que afeta o setor, tanto reduzindo danos à imagem da instituição como evitando as sanções administrativas, por exemplo, problemas no recredenciamento e suspensão da autonomia universitária e do processo seletivo (SILVA; COVAC. 2015. p. 22).

A amplitude setorial da aplicação do compliance faz com que sejam preservadas as bases, princípios éticos e normas de conduta que regem a sua formação, sendo sua aplicação alterada de acordo com o segmento de atuação, segundo os seus objetivos e as suas operações, de modo a garantir as boas práticas de conduta em seu respectivo eixo. Na educação privada, por tratar-se de um mercado extremamente competitivo e regulado, a aplicação do compliance é fundamental, contudo, deve-se identificar as suas especificidades para sua implementação. Silva e Covac destacam essa matriz própria de compliance como: (i) tratamento de conflitos de interesses; (ii)

identificação do risco de compliance setorial; (iii) planejamento de políticas e procedimentos; e (iv) auditoria legal, regulatória e acadêmica. (2015, p. 24).

Destaca-se a realização da auditoria, fundamental para a aplicação de monitoramentos e testes regulares, com o objetivo de averiguar se as atividades da empresa estão de acordo com o planejado. Trata-se de um mecanismo interno de avaliação, ao passo que o compliance faz parte da estrutura de controle institucional, acompanhando os pontos falhos de uma auditoria, por exemplo. A sua divisão em legal, regulatória e acadêmica reflete questões da educação superior em si: a auditoria legal, essencial em todo compliance, implica a revisão da documentação jurídica e administrativa; já a auditoria regulatória, consiste na identificação de deficiências e as respectivas recomendações de ações corretivas dentro de um marco regulatório, neste caso, os atos regulatórios do Ministério da Educação; por fim, a auditoria acadêmica, é a avaliação da situação da organização educacional como um todo, verificando a adequação de atividades e processos acadêmicos à leis, regulamentos e políticas institucionais. As três formam um tripé indissociável no controle do risco de compliance, minimizando custos e perdas, e favorecendo o cumprimento de metas da instituição com a qualidade exigida pelo poder público. 
Quando da implantação de um programa de compliance em uma instituição, deve-se analisar os riscos de compliance, identificando possíveis aspectos de desvios ou inconformidades, normalmente próprios do setor:

[...] pode-se inferir que a função de compliance emerge como determinante para subsidiar gestores educacionais no gerenciamento dos riscos próprios do setor, como o risco de sanções regulatórias (ex.: perda de autonomia), perdas financeiras (ex.: exclusão do Prouni ou Fies), perdas reputacionais decorrentes dos processos de avaliação (ex. divulgação de Índice Geral de Cursos insatisfatório), risco assistencial (ex.: não concessão do Certificado de Entidade Beneficente de Assistência Social conferido às entidades filantrópicas), risco judicial (ex.: ajuizamento de ações trabalhistas e consumeristas decorrentes da atividade educacional), risco regulamentar (ex. não observância das regras internas e códigos de conduta), risco societário (ex.: conflito de interesses), etc. Trata-se do chamado risco de compliance, ou seja, o risco de não conformidade com a legislação educacional de regência e com a política institucional adotada. (SILVA. 2013)

A partir da análise dos riscos, é criado o programa de compliance, estabelecendo a criação de procedimentos, controles e mecanismos de gestão, com o objetivo de minimizar os riscos. Destaca-se a definição de áreas de compliance, com gestores responsáveis por cada setor, assegurando que todos os cenários de risco estejam protegidos, podendo ser diminuídos ou eliminados, resguardando a integridade da instituição.

Analisando-se algumas matrizes de compliance aplicadas em universidades estrangeiras ${ }^{3}$, é possível observar a diversa gama de áreas que são definidas em cada uma delas, e algumas particulares a uma instituição de ensino superior. Além das áreas de compliance esperadas em qualquer empresa, e daquelas de gestão de uma instituição de ensino (como por exemplo: admissões, privacidade dos registros dos alunos, administração de pesquisa, entre outros), verificase que uma área foi constante nas matrizes avaliadas: a "Scientific Misconduct", isto é, a má conduta científica. Mesmo nas universidades que não disponibilizam as suas matrizes de compliance, este tópico é tratado de alguma forma em seus websites ${ }^{4}$, destacando qual a conduta a ser tomada nessa hipótese de "não compliance".

E é no combate a esta má conduta científica, na qual a ética é deixada de lado para que pesquisadores, professores e alunos possam atingir fins pessoais, que surge nas Universidades uma importância peculiar e fundamental de um programa de compliance. Isso ocorre, ainda, pela necessidade de educar os pesquisadores, sejam eles discentes ou docentes das Instituições de Ensino Superior, das práticas e condutas éticas, tendo em vista que há legislação e regras definidas por instituições de prestígio sobre o assunto. Pode-se citar sobre o assunto as normas de Vancouver (ICMJ, 2019), regras para a publicação de trabalhos no âmbito das ciências da saúde que tem relevância internacional também em outras áreas, sendo utilizada como regra na submissão de artigos em periódicos estrangeiros. Com atualização frequente, publicam-se além das normas de aspecto formal, recomendações de conduta para os autores, que abordam desde a autoria do trabalho até as responsabilidades de submissão e de publicação.

Ao tratar da autoria de um trabalho científico, verifica-se que é um dos aspectos que se relaciona fortemente a casos de má conduta acadêmica, não apenas em se tratando do amplamente

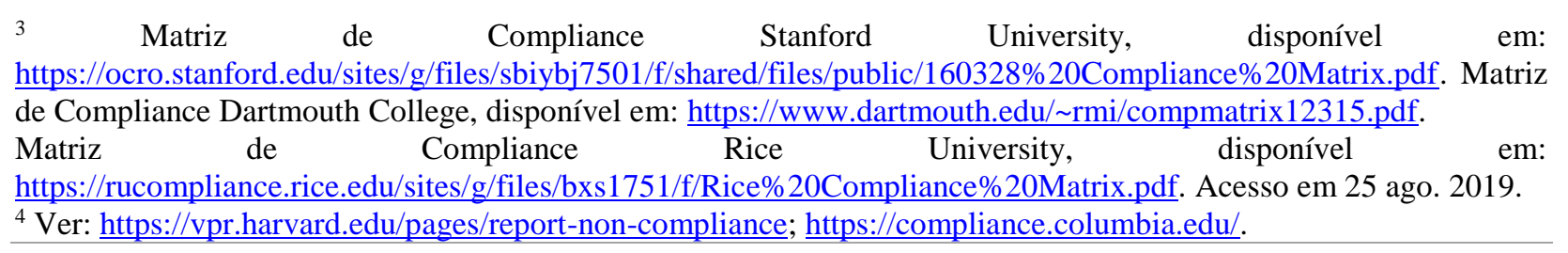

Revista de Direito Brasileira | Florianópolis, SC | v. 26 | n. 10 | p. 457-470 | Mai./Ago. 2020 
conhecido e combatido plágio, mas também da má atribuição de autoria. Nesse aspecto, as normas de Vancouver descrevem exatamente o que qualifica uma pessoa como autor.

Em resposta aos casos de má conduta científica, em 2013, a Universidade Federal do Rio de Janeiro (UERJ) foi a primeira instituição do Brasil a criar, através da Portaria 8645 de 30 de julho de 2013, uma comissão unicamente para tratar de questões relacionadas à integridade da pesquisa, a Câmara Técnica de Ética em Pesquisa (CTEP), com o objetivo de promover o desenvolvimento da ética em todas as etapas da pesquisa realizadas na instituição, propondo políticas e ações educativas e assessorando a sua Pró-Reitoria de Pós-Graduação e Pesquisa nas demandas relacionadas à ética em pesquisa (UERJ, 2019).

No Estado de São Paulo, duas universidades federais, a UFABC e a UFSCar criaram órgãos internos dedicados à promoção de boas práticas científicas e apuração de casos de má conduta, tornando-se as primeiras universidades públicas do Estado a criar estruturas para coordenar ações de educação e prevenção e examinar alegações de desvios (RAMOS, 2015).

Mais recente, em abril de 2017, a FAPESP anunciou que planejava bloquear recursos para universidades que não tivessem uma política clara de boas práticas acadêmicas. Em 2020, este bloqueio ainda não ocorreu, mas esta declaração reflete a atual postura combativa da comunidade científica, e os seus pequenos passos em prol da integridade na pesquisa. (MORAES, 2017). A ética é vista como um requisito primordial para a respeitabilidade da IES, assim como ocorre no ambiente corporativo.

Assim, a imagem de uma Instituição de Ensino Superior (IES), e o seu envolvimento ou não em casos de má conduta científica, é fundamental para determinar a sua respeitabilidade no meio acadêmico e a sua competitividade com outras instituições. A existência de um programa de compliance por si só demonstra o comprometimento da IES em combater tais atos por parte do seu corpo docente e discente, uma chancela do seu combate a dilemas morais.

Trata-se da responsabilidade das instituições de pesquisa, que devem preservar a integridade ética das pesquisas conduzidas em seu âmbito. Sobre isso, a FAPESP afirma que

As instituições de pesquisa compartilham com os pesquisadores individuais a responsabilidade pela preservação da integridade ética da pesquisa científica. Elas são as responsáveis principais pela promoção de uma cultura de boa conduta científica entre os pesquisadores e estudantes a ela vinculados, assim como pela prevenção, investigação e punição de más condutas científicas que ocorram em seu âmbito. (FAPESP, 2014, p. 35).

A esse respeito, Irene Patrícia Nohara alerta que não obstante a palavra compliance remeta, em sentido literal, à conformidade de regras e procedimentos, para que efetivamente haja a criação de uma cultura de integridade nas organizações há a necessidade de uma postura mais proativa em vez de um olhar reativo. Segundo a autora, a ideia de se estimular o desenvolvimento de um programa de integridade efetivo diz respeito muito mais a uma preocupação de melhoria da cultura organizacional, rumo à introjeção de parâmetros éticos, do que a simples intenção de mitigar efeitos de uma possível conduta contra a administração (NOHARA, 2019, p. 29).

Considerando-se a importância de uma postura proativa na criação de um programa de integridade nas Instituições de Ensino Superior, os dirigentes do Escritório de Assuntos Acadêmicos da Universidade da Califórnia, órgão responsável pelo todo tipo de apoio ao trabalho do corpo docente, relataram a questão das investigações de má conduta e a necessidade da prevenção de tais situações:

As investigações de má conduta dos professores são estressantes e desagradáveis. Além do sentimento de angústia que eles criam, as investigações podem culminar em ações disciplinares sérias (incluindo demissão) para o membro do corpo docente. Além disso, algumas alegações de má conduta terminam em litígios 
civis, o que é caro e difícil para todos os envolvidos. Assim, para apoiar seus professores, funcionários e estudantes, as universidades devem desenvolver estratégias para mitigar ou prevenir situações que culminem em alegações de má conduta. $^{5}$ (BINDER; FRIEDLI; FUENTES-AFFLICK. 2016, p.175).

Trata-se, portanto, de verdadeiro desafio que abala a estrutura dos comportamentos das pessoas que compõe a organização, seja ela pública ou privada, relacionado, principalmente, a mudança cultural.

Somente assim, criando-se esta cultura de integridade na produção científica, os pesquisadores diligentes, que produzem contribuições genuínas para a sociedade, serão valorizados e trarão prestígio às suas instituições.

\section{CONSIDERAÇÕES FINAIS}

A evolução e os avanços sociais e políticos nas sociedades democráticas permitiram a expansão das instituições de governança do Estado à medida que o exercício da cidadania se aprofundou. A pressão social faz com que tais sociedades passem a definir os mecanismos pelos quais seus governantes são monitorados impondo-lhe um conjunto de regras formais resultantes da interação de diferentes atores sociais.

Assim, o exercício e o cumprimento da lei passam a ser função não somente do aparato legal existente, mas também da pressão informal exercida pelas instituições e sociedade civil no cumprimento e na melhoria dessas regras.

Tal realidade se expandiu para os mais diversos setores sociais, de forma que, analogamente, todos os tipos de organizações, inclusive as privadas, também criam mecanismos de governança para lidar com a delegação de poder.

Nesse cenário surge a governança corporativa e, a partir de seus conceitos, os programas de compliance, cujo desafio central é a minimização de assimetrias e conflitos de interesses inerentes à delegação de poder através do alinhamento da empresa na busca de eficiência e eficácia da atividade das organizações.

Em relação às universidades, constata-se que os conflitos éticos e legais inerentes a sua atividade podem se dar tanto no âmbito externo, em sua relação com os entes públicos, como no âmbito interno, no exercício de suas próprias atividades, tal como a produção científica.

Dessa forma, conforme se defendeu no último tópico do presente trabalho, as universidades devem possuir políticas e procedimentos para lidar, além das fraudes e práticas corruptas, com as questões de má conduta na pesquisa, sendo o programa de compliance o meio eficaz para criar uma cultura de integridade nas instituições de ensino superior, através da conscientização, investigação, prevenção dos riscos e correção das irregularidades.

Ademais, para além da questão de preservação de riscos, os programas de integridade nas instituições de ensino superior ainda conferem uma imagem positiva para as mesmas, tendo em vista que mostra que sua direção está comprometida com a legalidade em suas ações e com a boa conduta científica, conscientizando seu corpo docente e discente e impondo-lhes, de certa forma, o cumprimento de normas legais e éticas.

Portanto, conclui-se que não somente é possível, mas necessária, a implementação de programas de integridade nas instituições de ensino superior para garantia da ética e da integridade

\footnotetext{
5 Tradução nossa. Original em inglês: “Investigations of faculty misconduct are stressful and unpleasant. In addition to the sense of distress they create, investigations may culminate in serious disciplinary action (including dismissal) for the faculty member. In addition, some allegations of misconduct end in civil litigation, which is expensive and difficult for everyone involved. Thus, to support their faculty, staff, and students, universities should develop strategies to mitigate or prevent situations that culminate in allegations of misconduct".
}

Revista de Direito Brasileira | Florianópolis, SC | v. 26 | n. 10 | p. 457-470 | Mai./Ago. 2020 
em suas ações, devendo-se, acima de tudo, promover a mudança de uma cultura no setor para garantia da boa conduta em suas atividades e na pesquisa científica.

\section{REFERÊNCIAS}

ANDRADE, Adriana; ROSSETTI, José Paschoal. Governança corporativa: fundamentos, desenvolvimento e tendências. 2. ed. - atual. e ampl. São Paulo: Atlas, 2006.

ANTONIK, Luis Roberto. Compliance, Ética, responsabilidade Social e Empresarial. $1^{\text {a }}$ ed. Rio de Janeiro: Alta Books, 2016.

BECHT, Marco; BOLTON, Patrick; ROELL, Ailsa. Corporate governance and control. NBER working paper series. 2002. Disponível em: http// www.nber.org/papers/w9371. Acesso em: jun. 2018.

BINDER, Renée; FRIEDLI, Amy; FUENTES-AFFLICK, Elena MD. The New Academic Environment and Faculty Misconduct. Academic Medicine, v. 91, n. 2, p 175-179, fev.2016. Disponível em: https://journals.1ww.com/academicmedicine/FullText/2016/02000/The_New_Academic_Environ ment_and_Faculty.16.aspx. Acesso em:

CAPES, Coordenação de Aperfeiçoamento de Pessoal de Nível Superior. História e Missão. 2008. Disponível em: https://www.capes.gov.br/historia-e-missao. Acesso em: 29 ago. 2019.

CHIARELLO, Felipe; SCALISSE, Amanda. A exigência de compliance nas contratações públicas. In: MESSA, Ana Flávia; DOMINGUES, Paulo de Tarso; ESTEVES, João Luiz Martins (orgs.). Governança, compliance e corrupção. São Paulo: Almedina, 2019, p. 209 a 220.

CHIARELLO, Felipe; SCALISSE, Amanda. Compliance na Administração Pública. In: HIGA, Alberto Shinji; JUNIOR, Arthur Bezerra de Souza (orgs.). Temas atuais de Direito Público: Estudos em homenagem ao Professor Toshio Mukai. Londrina: Thoth, 2019, p. 361 a 374.

DARTMOUTH COLLEGE. Compliance Matrix. Disponível em: https://www.dartmouth.edu/ rmi/compmatrix12315.pdf. Acesso em 25 ago. 2019.

FANG, Ferric C.; STEEN, R. Grant; CASADEVALL, Arturo. Misconduct accounts for the majority of retracted scientific publications. Proceedings of the National Academy of Sciences of the United States of America (PNAS). 16 out. 2012, 109 (42). Disponível em: https://www.pnas.org/content/109/42/17028. Acesso em: 30 ago. 2019.

FAPESP, Fundação de Amparo à Pesquisa do Estado de São Paulo. Código de Boas Práticas Científicas. 2014. Disponível em: http://www.fapesp.br/boaspraticas/FAPESPCodigo_de_Boas_Praticas_Cientificas_2014.pdf. Acesso em: 29 ago. 2019.

FAPESP, Fundação de Amparo à Pesquisa do Estado de São Paulo. Processo 16/307. 2019. Disponível em: http://www.fapesp.br/13491. Acesso em: 15 maio 2019.

FLORÊNCIO FILHO, Marco Aurélio Pinto; ZANON, Patricie Barricelli. A efetividade das políticas públicas de criminal compliance para a prevenção da corrupção no Brasil. In: MESSA, 
Ana Flávia; DOMINGUES, Paulo de Tarso; ESTEVES, João Luiz Martins (orgs.). Governança, compliance e corrupção. São Paulo: Almedina, 2019, p. 413 a 434.

IBGC, Instituto Brasileiro de Governança Corporativa. Código das melhores práticas de governança corporativa. 5.ed. / Instituto Brasileiro de Governança Corporativa. - São Paulo, SP: IBGC, 2018, $5^{\text {a }}$ reimpressão. 108p. Disponível em: http://www.ibgc.org.br/userfiles/files/Publicacoes/Publicacao-

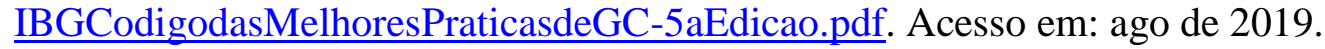

ICMJ, International Committee of Medical Journal Editors. Recommendations for the Conduct, Reporting, Editing, and Publication of Scholarly Work in Medical Journals. Dez. 2019. Disponível em: http://www.icmje.org/recommendations/. Acesso em: 10 maio 2020.

MACHADO FILHO, Cláudio Antônio Pinheiro. Governança e responsabilidade corporativa: interface e implicações no ambiente contemporâneo. In: Comunicação, governança e organizações [recurso eletrônico] / org. Luiz Alberto de Farias, Valéria de Siqueira Castro Lopes. - Dados Eletrônicos. - Porto Alegre: EDIPUCRS, 2016. 90 p. Disponível em: http://www.pucrs.br/edipucrs/. Acesso em: jun. 2019.

MARCUS, Adam. Elsevier weighs in on Brazilian fraud case. 2011. Disponível em: http://retractionwatch.com/2011/03/29/elsevier-weighs-in-on-brazilian-fraud-case/. Acesso em: 06 set. 2019.

MARCUS, Adam. Hazardous materials: Elsevier retracts 11 chemistry papers from Brazilian group, citing fraud. 2011. Disponível em: https://retractionwatch.com/2011/03/28/hazardousmaterials-elsevier-retracts-11-chemistry-papers-from-brazilian-group-citing-fraud/. Acesso em: 06 set. 2019.

MASSINI-CAGLIARI, Gladis. Identidade das Ciências Humanas e métricas de avaliação: Qualis periódicos e classificação de livros. Revista Brasileira de Pós-Graduação, v. 9, n. 18, 31 dez. 2012. Disponível em: http://ojs.rbpg.capes.gov.br/index.php/rbpg/article/view/366. Acesso em: 10 maio 2020.

MORAES, Fernando Tadeu. Cultura sólida de integridade na pesquisa ainda engatinha no país. 2017. Disponível em: https://www1.folha.uol.com.br/ciencia/2017/12/1941962-cultura-solida-deintegridade-na-pesquisa-ainda-engatinha-no-pais.shtml. Acesso em: 29 ago. 2019.

NOHARA, Irene Patrícia. Lei anticorrupção empresarial e compliance: programa de compliance efetivo e cultura de integridade. In: NOHARA, Irene Patrícia; PEREIRA, Flávio de Leão Bastos (orgs.). Governança, Compliance e Cidadania. $2^{a}$ edição. São Paulo: Revista dos Tribunais, 2019, p. 21 a 34.

RAMOS, Leo. Universidades promovem integridade. Pesquisa Fapesp, São Paulo, n. 236, p.9, out. 2015. Disponível em: https://revistapesquisa.fapesp.br/2015/10/14/universidades-promovemintegridade/?cat=boas-praticas. Acesso em: 30 ago. 2019.

REINACH, Fernando. Darwin e a prática da "Salami Science". 2013. Disponível em: http://www.estadao.com.br/noticias/impresso,darwin-e-a-pratica-da-salami-science1026037,0.htm. Acesso em: 29 ago. 2019. 
RICE UNIVERSITY. Compliance Matrix. Disponível em: https://rucompliance.rice.edu/sites/g/files/bxs1751/f/Rice\%20Compliance\%20Matrix.pdf. Acesso em 25 ago. 2019.

RODE, Sigmar de Mello; CAVALCANTI, Bruno das Neves. Ética em autoria de trabalhos científicos. Pesqui. Odontol. Bras., São Paulo, v. 17, supl. 1, p. 65-66, maio 2003. Disponível em: http://www.scielo.br/scielo.php?script=sci_arttext\&pid=S151774912003000500010\&lng=pt\&nrm=iso. Acesso em: 10 maio 2020.

SAAVEDRA, Giovani Agostini. Panorama do compliance no Brasil: avanços e novidades. In: NOHARA, Irene Patrícia; PEREIRA, Flávio de Leão Bastos (orgs.). Governança, Compliance e Cidadania. $2^{a}$ edição. São Paulo: Revista dos Tribunais, 2019, p. 35 a 47.

SANTOS, Larissa Dias Puerta dos; PUGA, Bruna Azzari. A Pesquisa Jurídica Brasileira e suas Peculiaridades no Século XXI: Os Atuais Mecanismos de Apuração da Qualidade e os Desvirtuamentos dos seus Objetivos. Revista de Pesquisa e Educação Jurídica. Goiânia, v. 5, n.1, p. 36-52, Jan/jun. 2019. Disponível em:

https://www.indexlaw.org/index.php/rpej/article/view/5543. Acesso em: 10 maio 2020.

SARCEDO, Leandro. Compliance e responsabilidade penal da pessoa jurídica: construção de um novo modelo de imputação baseado na culpabilidade corporativa. São Paulo: LiberArs, 2016., p. 41.

SILVA, Daniel Cavalcante. Educação e compliance: uma nova perspectiva no setor educacional. Revista Jus Navigandi. Teresina, ano 18, n.3624, 3 jun. 2013. Disponível em: https://jus.com.br/artigos/24582. Acesso em: 24 ago. 2019.

SILVA, Daniel Cavalcante; COVAC, José Roberto. Compliance como boa prática de gestão no ensino superior privado. São Paulo: Saraiva. 2015.

STANFORD UNIVERSITY. Compliance Matrix. Disponível em: https://ocro.stanford.edu/sites/g/files/sbiybj7501/f/shared/files/public/160328\%20Compliance\%2 0Matrix.pdf. Acesso em 25 ago. 2019.

TENÓRIO, Robinson Moreira; ANDRADE, Maria Antonia Brandão. A avaliação da educação superior no Brasil: desafios e perspectivas. In: LORDÊLO, José Albertino Carvalho; DAZZANI, Maria Virgínia. (Org.). Avaliação educacional: desatando e reatando nós. Salvador: EDUFBA, 2009. Disponível em: https://repositorio.ufba.br/ri/bitstream/ri/5627/1/Avaliacao_educacional.pdf. Acesso em: 24 ago. 2019.

UNIVERSIDADE ESTADUAL DO RIO DE JANEIRO (UERJ). Pró-Reitoria de Pós-graduação e Pesquisa. CTEP: Objetivo. Disponível em: http://app.pr2.ufrj.br/pr2/objetivoCTEP. Acesso em: 29 ago. 2019. 